\title{
Cerebral Cavernous Malformations: An Update on Prevalence, Molecular Genetic Analyses, and Genetic Counselling
}

\author{
Stefanie Spiegler ${ }^{\mathrm{a}}$ Matthias Rath ${ }^{\mathrm{a}}$ Christin Paperlein $^{\mathrm{b}} \quad$ Ute Felbor $^{\mathrm{a}}$ \\ a Department of Human Genetics, University Medicine Greifswald and Interfaculty Institute of Genetics and \\ Functional Genomics, University of Greifswald, and ${ }^{\mathrm{b}}$ Institute of Diagnostic Radiology and Neuroradiology, \\ University Medicine Greifswald, Greifswald, Germany
}

\section{Keywords}

Cerebral cavernous malformations · Genetic counselling · Molecular genetics $\cdot$ Prevalence $\cdot$ Vascular malformation

\begin{abstract}
Based on the latest gnomAD dataset, the prevalence of symptomatic hereditary cerebral cavernous malformations (CCMs) prone to cause epileptic seizures and stroke-like symptoms was re-evaluated in this review and calculated to be 1:5,400-1:6,200. Furthermore, state-of-the-art molecular genetic analyses of the known CCM loci are described which reach an almost $100 \%$ mutation detection rate for familial CCMs if whole genome sequencing is performed for seemingly mutation-negative families. An update on the spectrum of CCM1, CCM2, and CCM3 mutations demonstrates that deep-intronic mutations and submicroscopic copynumber neutral genomic rearrangements are rare. Finally, this review points to current guidelines on genetic counselling, neuroimaging, medical as well as neurosurgical treatment and highlights the formation of active patient organizations in various countries.

(c) 2018 S. Karger AG, Basel
\end{abstract}

\section{KARGER}

(C) 2018 S. Karger AG, Basel

E-Mail karger@karger.com

www.karger.com/msy
Cerebral cavernous malformations (CCM; OMIM $116860,603284,603285$ ) are composed of enlarged, blood-filled endothelial compartments within the venous-capillary vascular bed of the central nervous system. These multilobulated, often calcified vascular balls are characterized by a dysfunctional blood-brain barrier and leakiness due to insufficient tight and adherens junctions of the lining endothelial cells. They lack pericytes and vascular smooth muscle cells, and blood flow is low. However, recurrent and larger haemorrhages into the neighbouring brain parenchyma may lead to seizures and stroke-like symptoms such as (hemi)paresis, paraesthesias, visual disturbances, vertigo, and headaches depending on their extent and localization.

3T MRI is established as the gold standard for CCM detection. T2-weighted images reveal the characteristic mulberry- or popcorn-like appearance and a dark rim due to hemosiderin deposition after repeated bleedings (Fig. 1). Increased sensitivity can be achieved with T2* weighted gradient echo sequences and susceptibilityweighted images for early detection of small Zabramski type IV cerebral cavernomas, e.g., in the autosomal dominantly inherited familial form of CCM [Zabramski et al., 1994; Batra et al., 2009; Akers et al., 2017].

Prof. Dr. Ute Felbor, MD

Department of Human Genetics, University Medicine Greifswald Fleischmannstr. 43

DE-17475 Greifswald (Germany)

E-Mail felbor@uni-greifswald.de 

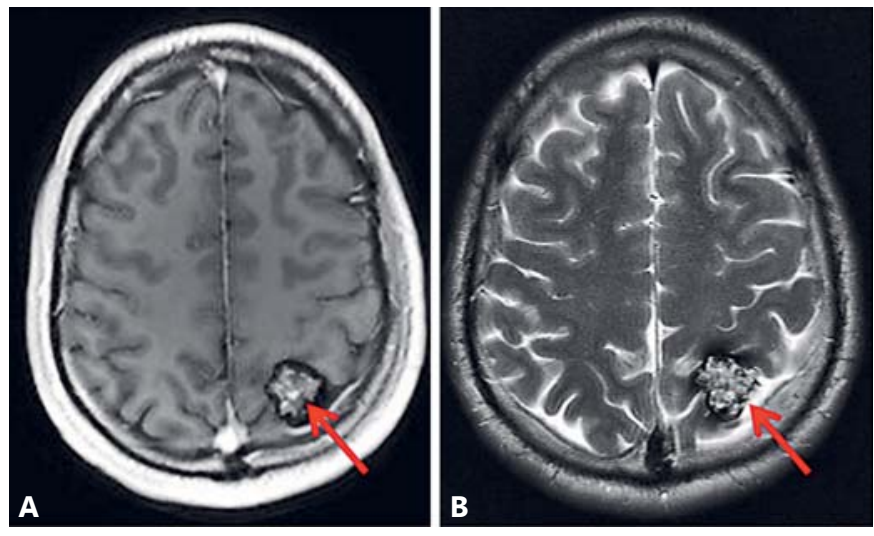

Fig. 1. T1-weighted (A) and T2-weighted (B) MRI of a 25-year-old proband with a cavernous malformation in his left posterior parietal lobe (red arrows). The Zabramski type II CCM with a maximum diameter of $23 \mathrm{~mm}$ shows the typical popcorn-like appearance and mixed signal intensities. The surrounding dark rim in T1 and T2 imaging is due to hemosiderin deposits.

\section{CCM Prevalence on the Basis of Large Genetic Databases}

Next to developmental venous anomalies, CCMs have been reported to be the second most prevalent type of vascular malformation of the central nervous system [Batra et al., 2009]. In a retrospective analysis of 24,535 autopsies, Otten et al. [1989] identified a total of 131 CCM carriers $(1: 187 ; 0.53 \%)$. A similar prevalence rate was found in a prospective imaging study of adults aged $50-89$ years that had been enrolled between 2004 and 2015 in the Mayo Clinic Study of Aging [Flemming et al., 2017]: CCMs were identified in 12 of 2.715 participants $(1: 226 ; 0.44 \%)$ by brain MRI on a 3T system. Multiple CCMs without associated developmental venous anomalies - an angioarchitectonic constellation suggestive of familial CCM - were identified in only 2 probands that were asymptomatic at the time of research MRI $(1: 1,358 ; 0.07 \%)$ [Flemming et al., 2017]. The proportion $(n=2 / 12 ; 17 \%)$ corresponds to a prospective, population-based cohort study in which 24 out of 139 (17\%) adults with CCMs had multiple lesions [Al-Shahi Salman et al., 2012]. However, neither family history nor molecular genetic analyses have been documented for these cases with multiple CCMs.

In February 2017, official access to the Genome Aggregation Database (gnomAD; version 2.0), an extension of the Exome Aggregation Consortium (ExAC) browser [Lek et al., 2016], became available. This dataset contains 123,136 exome and 15,496 whole-genome sequences of

Cerebral Cavernous Malformations individuals that originate from various ethnicities (East Asian, South Asian, non-Finnish European, Finnish, Ashkenazi Jewish, Latino, and African/African American).

Currently, 36 carriers of heterozygous frameshift, nonsense, and splice site mutations in the CCM genes are listed in the gnomAD database (Table 1). 13 of the 32 distinct mutations in CCM1 (12/22), CCM2 (1/9), and CCM3 $(0 / 1)$ have previously been identified in CCM families from different ethnicities and are already listed in the $\mathrm{Hu}$ man Gene Mutation Database as pathogenic (HGMD 2017.2). One of these (CCM1: c.1363C>T, p.Gln455*) was detected in a proband of the Latino cohort and is a common Hispanic founder mutation in south western regions of the USA [Sahoo et al., 1999]. Given a total number of 138,632 probands within gnomAD and a sufficient sequencing coverage, a mutation carrier frequency of $1: 3,851(\sim 0.03 \%)$ can be calculated, which is slightly lower than in the smaller ExAC database $(1: 3,373)$ [Spiegler et al., 2016]. Although information on high-resolution neuroimaging is not available from the aggregated gnomAD dataset, hereditary CCM can be assumed for these mutation carriers. However, these frequencies likely do not reflect the overall prevalence of familial CCM. Since symptomatic CCM patients often present with a striking clinical phenotype, loss-of-function mutation carriers listed in gnomAD might primarily represent individuals with asymptomatic CCMs and onset of the disease later in life. On the assumption that CCM mutation carriers with an onset of CCM disease in childhood would not have been included in gnom $\mathrm{AD}$, the overall prevalence of hereditary CCM can be extrapolated from this dataset to be in the range of approximately 1:3,300$1: 3,800$ since one third of CCM probands are minors and every fifth is under the age of 10 [Spiegler et al., 2014]. Although this estimation might be rather rough and ignores CCM1-3 CNVs and the possibility of pathogenic missense variants, it is in agreement with the assumption that $6-7 \%$ of all CCM cases are hereditary [Batra et al., 2009]. The prevalence of symptomatic mutation carriers will be even lower (roughly 1:5,400-1:6,200) as CCM penetrance is incomplete and has been reported to be 62.2\% [Denier et al., 2006]. By definition, familial CCM is therefore a rare disease.

The gnomAD dataset does also reflect the locus-specific penetrance of familial CCM. While 24 CCM1 mutation carriers are listed here, only a single proband with a heterozygous CCM3 splice site mutation was identified (Table 1). This uneven distribution between pathogenic variants in CCM1, CCM2, and CCM3 demonstrates that the latter is less tolerant to mutations and supports the

Mol Syndromol 2018;9:60-69 DOI: $10.1159 / 000486292$ 
Table 1. Loss-of-function mutations in CCM1, CCM2, and CCM3 that are currently listed in gnomAD

\begin{tabular}{|c|c|c|c|c|c|}
\hline Gene & Nucleotide change & $\begin{array}{l}\text { Predicted protein } \\
\text { change }\end{array}$ & $\begin{array}{l}\text { Molecular } \\
\text { mechanism }\end{array}$ & $\begin{array}{l}\text { Hetero- } \\
\text { zygotes, } n\end{array}$ & Reference \\
\hline \multirow[t]{21}{*}{$\begin{array}{l}\text { CCM1 } \\
\text { (LRG_650t1) }\end{array}$} & $\begin{array}{l}\text { c.141_145delAAAGA } \\
\text { c.146_147delGA }\end{array}$ & $\begin{array}{l}\text { p.Arg49Glufs*13 } \\
\text { p.Arg49Lysfs*14 }\end{array}$ & $\begin{array}{l}\text { frameshift } \\
\text { frameshift }\end{array}$ & $\begin{array}{l}1 \\
2\end{array}$ & $\begin{array}{l}\text { n.d. } \\
\text { Posey et al., } 2017\end{array}$ \\
\hline & c. $151 \mathrm{~A}>\mathrm{T}$ & p.Lys51* & stop gained & 1 & n.d. \\
\hline & c. $175 \mathrm{C}>\mathrm{T}$ & p.Gln $59^{*}$ & stop gained & 1 & n.d. \\
\hline & c. $196 \mathrm{C}>\mathrm{T}$ & p.Gln $66^{*}$ & stop gained & 1 & Gianfrancesco et al., 2007 \\
\hline & c. $250 \mathrm{C}>\mathrm{T}$ & p.Gln $84^{*}$ & stop gained & 1 & n.d. \\
\hline & c. $262+1 \mathrm{G}>\mathrm{T}$ & p.? & splice donor & 1 & n.d. \\
\hline & c. $418 \mathrm{C}>\mathrm{T}$ & p.Arg140* & stop gained & 1 & Melis et al., 2014 \\
\hline & c.457dupA & p.Thr153Asnfs*10 & frameshift & 1 & Riant et al., 2013 \\
\hline & c. $535 \mathrm{C}>\mathrm{T}$ & p.Arg179* & stop gained & 1 & Cavé-Riant et al., 2002 \\
\hline & c.870dupT & p.Pro291Serfs*8 & frameshift & 2 & n.d. \\
\hline & c. $880 \mathrm{C}>\mathrm{T}$ & p.Arg294* & stop gained & 1 & Riant et al., 2013 \\
\hline & c.1109delT & p.Ile370Lysfs*6 & frameshift & 1 & n.d. \\
\hline & c. $1147-2 A>G$ & & splice acceptor & 1 & n.d. \\
\hline & c. $1363 \mathrm{C}>\mathrm{T}$ & p.Gln $455^{*}$ & stop gained & 1 & Sahoo et al., 1999 \\
\hline & c.1360_1363delTCTC & p.Ser454Lysfs*40 & frameshift & 1 & Cavé-Riant et al., 2002 \\
\hline & c. $1411+2 \mathrm{~T}>\mathrm{A}$ & p.? & splice donor & 1 & n.d. \\
\hline & c. $1498 \mathrm{C}>\mathrm{T}$ & p.G $\ln 500^{*}$ & stop gained & 1 & Riant et al., 2013 \\
\hline & c. $1563+1 \mathrm{G}>\mathrm{A}$ & & splice donor & 1 & de Vos et al., 2017 \\
\hline & c.1688_1689delAT & p.Tyr563Trpfs*4 & frameshift & 1 & Denier et al., 2004b \\
\hline & c.1717_1720delCAAG & p.Gln573Valfs*3 & frameshift & 1 & Limaye et al., 2007 \\
\hline & c.1933_1936dupTTTA & p.Thr646Ilefs*10 & frameshift & 1 & n.d. \\
\hline \multirow{9}{*}{$\begin{array}{l}\text { CCM2 } \\
\text { (LRG_664t2) }\end{array}$} & c. $55 \mathrm{C}>\mathrm{T}$ & p.Arg19* & stop gained & 1 & Verlaan et al., 2004 \\
\hline & c. $472+1 \mathrm{G}>\mathrm{A}$ & p.? & splice donor & 1 & n.d. \\
\hline & c. $472+1 \mathrm{G}>\mathrm{C}$ & p.? & splice donor & 3 & n.d. \\
\hline & c.495delC & p.Ser166Alafs $* 48$ & frameshift & 1 & n.d. \\
\hline & c. $803+1 G>C$ & p.? & splice donor & 1 & n.d. \\
\hline & c.805dupT & p.Cys269Leufs*4 & frameshift & 1 & n.d. \\
\hline & c.1017delG & p.Gln340Serfs* 14 & frameshift & 1 & n.d. \\
\hline & c.1040_1044delAGTTC & p.Lys347Thrfs*11 & frameshift & 1 & n.d. \\
\hline & c.1234dupC & p.Arg412Profs*9 & frameshift & 1 & n.d. \\
\hline $\begin{array}{l}\text { CCM3 } \\
\text { (LRG_651t1) }\end{array}$ & c. $97-1 \mathrm{G}>\mathrm{A}$ & p.? & splice acceptor & 1 & n.d. \\
\hline
\end{tabular}

Mutations listed as low-confidence variants in the gnomAD browser have not been included. n.d., not described in the literature.

observation that CCM3 mutation carriers often manifest earlier in life with a more severe phenotype [Denier et al., 2006, Cigoli et al., 2014, Spiegler et al., 2014, Shenkar et al., 2015].

\section{Molecular Genetic Analyses: From Stepwise Conventional Sequencing to Comprehensive NGS Gene Panels and Whole Genome Sequencing}

The identification of a pathogenic variant in either CCM1 (KRIT1; Laberge-le Couteulx et al. [1999]; Sahoo et al. [1999]), CCM2 (Malcavernin; OSM; Liquori et al.
[2003]; Denier et al. [2004a]) or CCM3 (PDCD10, TFAR15; Bergametti et al. [2005]) is essential to confirm the diagnosis of hereditary CCM and to guide genetic counselling for at-risk family members. Since mutational hot spots in the 3 genes cannot be defined (Fig. 2), a stepwise screening approach is generally not reasonable any more unless an individual has Hispanic ancestry of Mexican or southwest US-American descent [Akers et al., 2017] or originates from the Ashkenazi-Jewish population [Gallione et al., 2011]. Therefore, CCM molecular genetic analyses currently include targeted capture of all coding exons and exon/intron junctions followed by massively parallel sequencing and deletion/duplication 


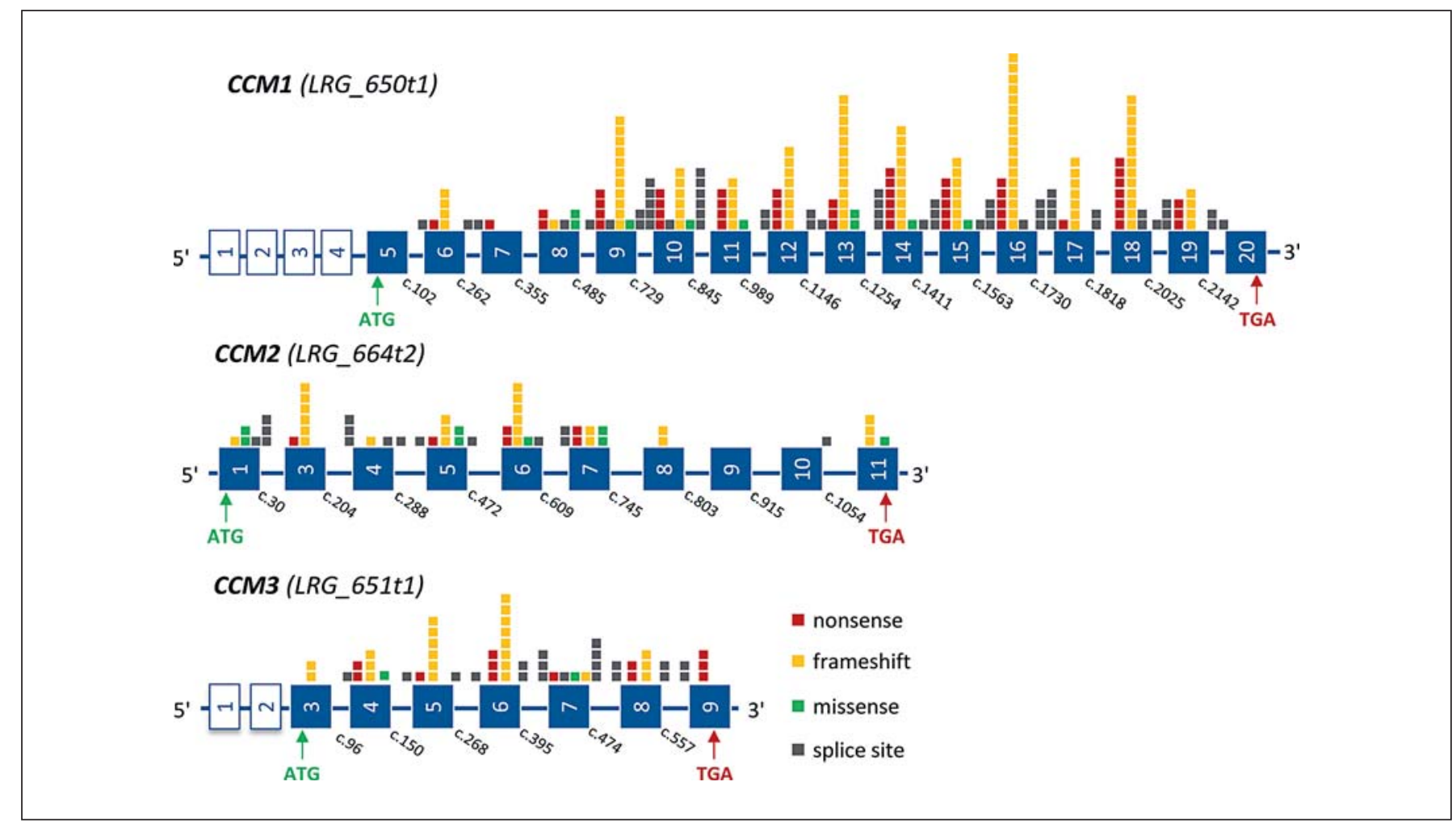

Fig. 2. Spectrum and distribution of known mutations in CCM1, CCM2, and CCM3. The organization of the main transcripts is schematically depicted with blue boxes indicating protein coding exons, clear boxes representing non-coding exons, and blue lines indicating intronic sequences [exon numbering according to the locus reference genomic (LRG) database]. The last coding nucleo- tide of each exon is given below each box. Nonsense, frameshift, missense, and splice site mutations listed in HGMD 2017.2 are depicted in the upper part of each subpanel. Small deletions, insertions and indel variants that affect splicing have been classified as splice mutations. ATG, start codon; TGA, stop codon. Large deletions and insertions are not included. screening of CCM1-3. Sequence variants identified by NGS are currently still confirmed by Sanger sequencing, although the quality of NGS and the target enrichment efficiency have improved over the last years and even hard-to-sequence regions such as the $5^{\prime}$-untranslated region of CCM2 which is known for its high GC content can be sufficiently covered if the panel is appropriately designed. In our experience, CNVs can also reliably be detected from NGS data in a streamlined workflow (Fig. 3). A further advantage of comprehensive NGS panels is that the parallel analysis of all 3 CCM genes facilitates the interpretation of rare variants of uncertain significance: An alternative molecular basis for CCM - i.e., a clearly pathogenic loss-of-function mutation in another CCM gene - is supporting evidence against the pathogenicity of a variant of uncertain significance [Schröder et al., 2014; Richards et al., 2015].

The mutation detection rate in a diagnostic context is highly dependent on the inclusion criteria which have been specified in Akers et al. [2017] and the scope of the analysis. Pathogenic variants can be identified in $87-98 \%$ of all cases with a positive family history [Denier et al., 2006; Stahl et al., 2008; Cigoli et al., 2014; Spiegler et al. 2014]. For apparently mutation-negative familial cases, pathogenic variants outside of the immediate diagnostic target region have been discussed. Since the thorough study of Denier et al. [2006], additional transcript analyses and cDNA sequencing led to the identification of a deep intronic CCM1 mutation (c.262+132_262+ 133delAA) in an individual of the French cohort who presented with developmental delay and 4 hemispheric CCM lesions that had been incidentally identified by MRI. This intronic deletion leads to the insertion of a 99 bp pseudoexon with a premature stop codon in the open reading frame and was also detected in his mother's and maternal grandfather's blood samples. Despite multiple cavernous lesions, both had no symptoms suggestive of CCM either [Riant et al., 2014]. Nevertheless, the clinical outcome of 


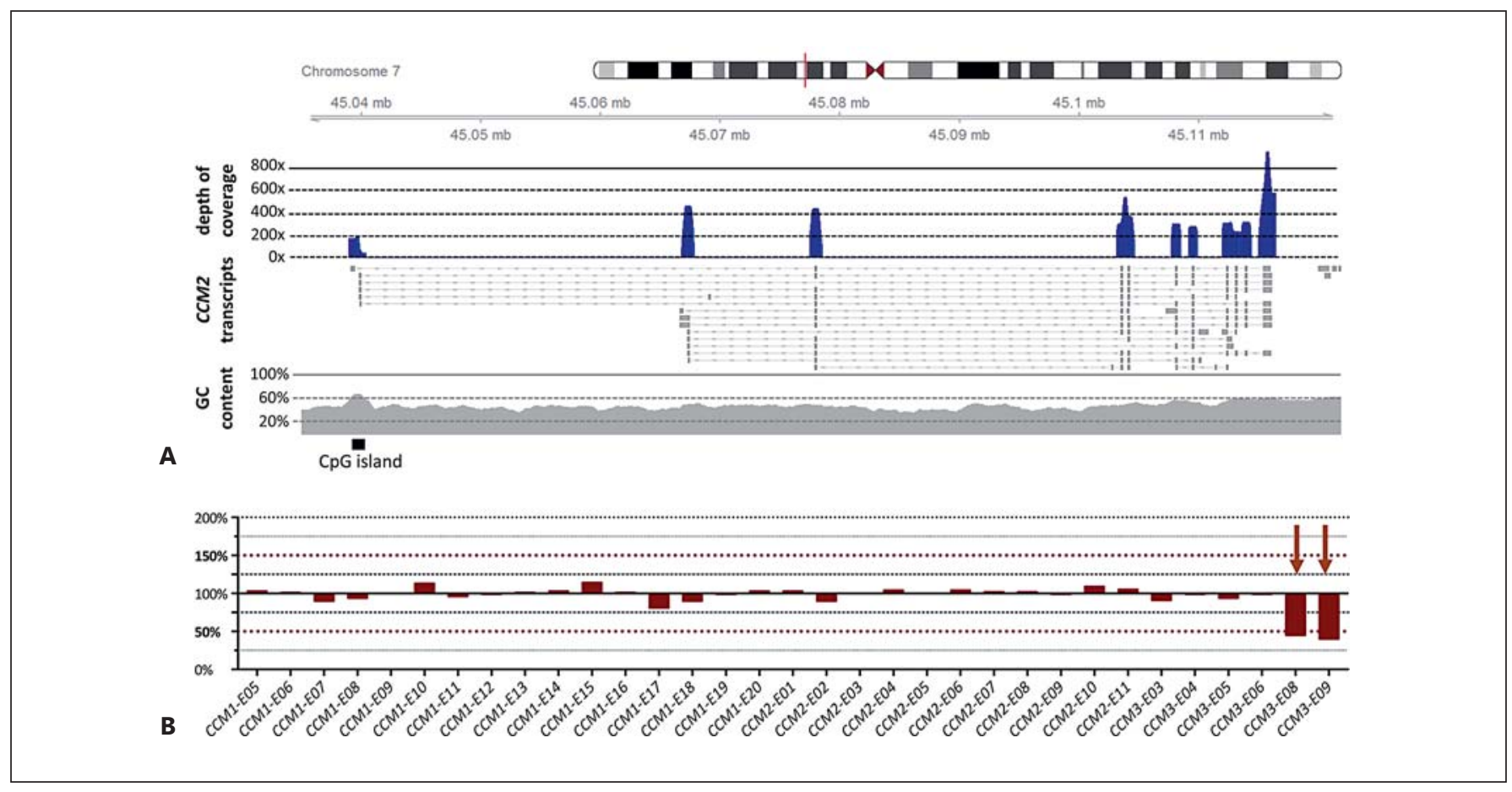

Fig. 3. Comprehensive genetic screening of CCM1-3 by targeted capture enrichment and NGS. A Representative diagnostic NGS data from our own cohort (unpublished data). The read depth across the coding regions of CCM2 is shown as coverage plot (dark blue); exon-intron structures of the ENSEMBL-listed CCM2 tran- scripts are shown below. A chromosome ideogram with the cytogenetic location of CCM2 (red line) is depicted in the upper part and the GC content is illustrated with $\mathrm{CpG}$ islands in the lower part. B Representative NGS-based CNV analysis demonstrating a heterozygous deletion of exon 8 and 9 of CCM3. individuals with deep intronic splice mutations cannot be predicted from the specific genotype. We have recently found the same intronic CCM1 deletion in an individual who presented with multiple CCMs and a brainstem haemorrhage (unpublished data). Although deep intronic splice mutations are a conceivable cause of CCM, a systematic NGS-based search did not reveal further pathogenic variants deep within the non-coding regions of CCM1-3 in our cohort and is therefore not part of the standard diagnostic work-up yet [Rath et al., 2017].

Our previous calculations regarding the mutation detection rate included one case that remained unsolved after conventional diagnostic analyses as well as NGS of the entire genomic CCM1-3 regions [Stahl et al., 2008; Spiegler et al., 2014; Rath et al., 2017]. Whole exome sequencing [Spiegler et al., 2016] and whole genome sequencing using filter strategies for autosomal dominant and recessive inheritance as well as de novo mutations in a triobased approach (unpublished data) did not reveal a genetic cause for her disease either. The currently 19-yearold woman first presented at the age of 5 years with seizures and a single supratentorial cavernous lesion that was neurosurgically resected and diagnosed as being a CCM histologically. She was referred to molecular genetics 3 years later since her father was reported to have had 2 intracranial bleedings at the age of 16 and 23 which had led to a major neurosurgical intervention in 1981. In light of the extensive negative genetic screening results as well as the fact that positive neuroimaging rather than positive family history is a more specific criterion for proven familiarity in a research context, somatic mosaicism in the daughter and a phenocopy or an alternative vascular malformation (e.g., venous, arteriovenous, or mixed vascular lesions) in the father may have to be considered in this family.

Given the exceptionally high mutation detection rates for familial CCM, the existence of a possible fourth gene harbouring germline mutations in individuals affected with CCM becomes rather unlikely 12 years after the identification of CCM3 [Bergametti et al., 2005]. The very few remaining seemingly CCM1-3 mutation-negative families with positive neuroimaging over several
64

Mol Syndromol 2018;9:60-69

DOI: $10.1159 / 000486292$
Spiegler/Rath/Paperlein/Felbor 
Table 2. Inclusion criteria for diagnostic molecular genetic testing of CCM carriers

Positive family history

Multiple CCMs without

- associated developmental venous anomaly or

- history of brain radiation

Data based on Akers et al. [2017]. CCM, cerebral cavernous malformation.

generations may rather carry a pathogenic variant outside the routinely screened exonic regions and immediate adjacent splice sites of the 3 known CCM genes or a copy number neutral genomic rearrangement involving either the CCM1, CCM2, or CCM3 gene. Most recently, we have clarified such a familial case in which only whole genome sequencing combined with an excellent bioinformatics pipeline resulted in the identification of a 24$\mathrm{kb}$ spanning inversion involving exon 1 of CCM2 [Spiegler et al., 2017].

\section{Detection of High-Level Mosaicism and Low-Level Somatic Mutations with NGS}

Similar to familial CCM, the detection rate for isolated cases with multiple CCMs depends on the inclusion criteria and mutation detection methods used. Previously, it ranged from 57 to $60 \%$ [Denier et al., 2006; Stahl et al., 2008; Spiegler et al., 2014]. However, the guidelines published by Akers et al. in 2017 (Table 2) recommend to include only those that neither present with an associated developmental venous anomaly [Dammann et al., 2017] nor with a history of brain radiation as this is a known risk factor for CCM formation [Heckl et al., 2002; Nimjee et al., 2006]. Following these recommendations, mutation detection rates higher than $75 \%$ appear to be realistic [Akers et al., 2017].

In light of incomplete CCM penetrance, a lack of neurological symptoms is insufficient to exclude CCM for at-risk family members. Targeted sequencing of DNA samples of both parents should be offered as part of the diagnostic work-up for apparently isolated CCM cases. Since parents do not always consent to predictive genetic testing, de novo mutations in CCM1-3 might not be as rare as previously thought [Lucas et al., 2001; Bergametti et al., 2005; Liquori et al., 2006; Stahl et al., 2008; Riant et al., 2013; Cigoli et al., 2014; Shenkar et al., 2015; Rath et

Cerebral Cavernous Malformations al., 2016]. NGS data may indicate mosaicism, but high coverage and a sophisticated validation are necessary for reliable clinical conclusions [Acuna-Hidalgo et al., 2015]. Consistent with literature reports, our experience suggests that CCM3 might be more prone to de novo mutational events than CCM1 and CCM2. Recently, we have identified another CCM3 de novo point mutation in a 2-year-old boy with global developmental delay, multiple CCMs, and a brainstem haemorrhage. The CCM3 splice mutation (c.474+5G $>A$ ) was detected with an alternate allele read frequency of $33-35 \%$ in lymphocyte and buccal mucosa DNA in independent NGS approaches and had most likely originated from an early postzygotic mutational event. Mosaicism was also suspected for a CCM3 gene deletion in another CCM case based on MLPA results [Rath et al., 2016]. Although the discrimination between germline mutation and high-level mosaicism might be of minor clinical relevance for the index case, it is important for genetic counselling of his/her relatives.

Not only high-level mosaicism, but also the other end of the spectrum - namely, low-level somatic mutations in CCM lesions - remain analytically challenging. In agreement with the hypothesis of a Knudsonian 2-hit mechanism, immunohistochemical analyses of cavernous lesions of 7 unrelated CCM1, CCM2, and CCM3 mutation carriers demonstrated loss of function for the corresponding CCM protein in cavernous, but not adjacent endothelial cells [Knudson, 1971; Pagenstecher et al., 2009]. Furthermore, biallelic somatic and germline mutations have been identified on nucleotide level in CCM lesions of familial cases with known pathogenic CCM1-3 variants [Gault et al., 2005, 2009; Akers et al., 2009]. Somatic mosaicism is also an explanation for isolated CCM cases without a known germline mutation. McDonald et al. [2014] have successfully identified somatic variants in 4 out of 11 sporadic CCM samples with NGS analyses. Notably, 2 CCM1 nonsense mutations that had been detected in one of these lesions were located in trans and demonstrated that 2 biallelic somatic mutations in cavernous endothelial cells are a possible explanation for mutation-negativity in standard molecular diagnostics [McDonald et al., 2014]. However, the validity of somatic mutations as the sole "second hit" mechanism in CCM pathogenesis is under debate as such variants cannot be identified in all CCM lesions and some of the mutations identified so far are in-frame deletions that cannot be classified as bona fide loss-of-function variants [Reich et al., 2003; Marini et al., 2004; McDonald et al., 2014]. Future studies with high-sensitivity techniques are necessary to address this open question in larger CCM cohorts.

Mol Syndromol 2018;9:60-69

DOI: $10.1159 / 000486292$ 


\section{Future Perspectives: How Genetic and Environmental Factors May Modify the CCM Phenotype}

As mentioned above, the course of the disease can vary significantly between individuals that share the same germline mutation even within a single CCM family [Lucas et al., 2003; Spiegler et al., 2014; Fauth et al., 2015]. Given that a second somatic mutation cannot be identified in all cases, it is reasonable to hypothesize that yet to be identified regulatory mechanisms and different expression levels of modifier genes may also trigger disease onset and contribute to incomplete disease penetrance and variable expressivity of CCM. Anticipation with respect to age of disease onset has been reported in some CCM families [Siegel et al., 1998a, b]. However, trinucleotide-repeat expansions do not belong to the mutation spectrum associated with CCM (Fig. 2). Furthermore, Netzer and colleagues [2009] found no evidence for progressive telomere shortening in CCM1 mutation carriers from a 3-generation family presenting with significantly earlier disease onset in the youngest generation [Kuhn et al., 2009].

\section{Genetic Counselling, Current Guidelines, and Patient Organizations}

Owing to the increasing availability of high-resolution brain imaging, a growing number of asymptomatic intracerebral cavernous malformations are currently identified incidentally. The haemorrhage rate per patient-year has been reported to be significantly lower in incidentally discovered groups when compared to symptomatic groups [Washington et al., 2010; Al-Holou et al., 2012; Al-Shahi Salman et al., 2012; Gross et al., 2016; Horne et al., 2016; Akers et al., 2017]. In a single-centre cohort of 107 individuals with CCM as an incidental finding, the only patient in whom a prospective haemorrhage was definitively related to the cavernous malformation was in fact diagnosed as having a familial form of CCM. It was concluded that the risk of future haemorrhage is low in patients presenting with an incidental CCM [Moore et al., 2014]. For familial CCM, higher annual haemorrhage rates, the occurrence of multiple CCMs at an earlier age, and the appearance of new lesions have been reported [Zabramski et al., 1994; Labauge et al., 2001; Shenkar et al., 2015].

Inclusion criteria for diagnostic molecular genetic testing are listed in Table 2 . The question of predictive analyses for at-risk relatives needs to be carefully discussed during genetic counselling. Obviously, exclusion of a pathogenic familial variant is the main potential advantage of predictive testing since it relieves relatives from uncertainties on the occasion of e.g. ordinary headaches, dizziness, or discomfort unrelated to CCM and renders neurological examinations and repeated brain imaging unnecessary. On the other hand, confrontation with a CCM mutation may enhance anxieties and warrants an MRI including gradient echo or susceptibilityweighted sequences in order to document the number, location, and stage of cavernous lesions. Follow-up MRI is recommended within 2 weeks after the onset or worsening of clinical symptoms [Akers et al., 2017]. Two out of 33 asymptomatic individuals with familial CCMs (range 1-85 lesions/individual) became symptomatic in a prospective 2-year follow-up study: One experienced a sudden haemorrhage within the brainstem, the other partial seizures [Labauge et al., 2001].

Mutation carriers should be informed that about $40 \%$ of CCM1-3 mutation carriers remain asymptomatic [Denier et al., 2006]. In addition, inter- and intrafamilial phenotypic variability is high and fulminant clinical courses of CCM are rather rare. An earlier and more severe disease manifestation has been reported for CCM3 mutation carriers when compared to CCM1 and CCM2 mutation carriers [Denier et al., 2006; Cigoli et al., 2014; Spiegler et al., 2014]. In a cohort of 18 CCM3 mutation carriers, the mean age at symptom onset was 12.6 years (range $0.25-52$ years) as opposed to a mean age at first overt haemorrhage of 30 years for familial cases carrying a CCM1 or CCM2 mutation (range 1-52 years) [Shenkar et al., 2015]. However, even with an increased lesion burden of more than 30 cavernomas, CCM3 mutation carriers may remain asymptomatic until the fifth decade but need to be prepared that they may develop a severe phenotype including dysarthria, multiple cranial nerve palsies, gait disturbances, and focal seizures later in life [Schröder et al., 2014]. Seizures are the predominant first symptom of supratentorial lobar CCMs, while brainstem lesions are primarily associated with cranial nerve palsy, hemiparesis, and other focal neurological deficits. Prior haemorrhage and brainstem location appear to confer a higher risk for symptomatic haemorrhage, while the annual re-hemorrhage rate has been reported to decline over time [AlHolou et al., 2012; Al-Shahi Salman et al., 2012; Gross et al., 2016; Horne et al., 2016; Gross and Du, 2017].

In spite of the growing knowledge on CCM pathophysiology, most clinical treatment decisions are still based on expert opinions and an individual risk-benefit
66

Mol Syndromol 2018;9:60-69 DOI: $10.1159 / 000486292$
Spiegler/Rath/Paperlein/Felbor 
analysis. The synopsis of guidelines that has recently been published by the American Angioma Alliance provides a useful roadmap for clinical CCM management, although high-level recommendations are still missing due to the lack of randomized and sufficiently powered clinical trials [Akers et al., 2017].

Patient organizations like the American Angioma Alliance (http://www.angiomaalliance.org/), the Cavernoma Alliance UK (https://www.cavernoma.org.uk/), the German "Bundesverband Angeborene Gefässfehlbildungen” (http://www.angiodysplasie.de/de/; http://www.kavernom.de/de/) and other national and international organizations are important partners to exchange experiences and provide support regarding personal, social, psychological, and medical issues that arise with the diagnosis of a rare disease such as familial CCM. In addition, these networks are extremely helpful because they maintain long-term contact between affected individuals and their families and communicate results from ongoing therapy studies back to patients.

\section{Conclusion}

With a calculated prevalence of 1:5,400-1:6,200, symptomatic hereditary CCMs belong to the group of rare diseases that can be transmitted in an autosomal dominant manner with incomplete penetrance and variable expressivity. A mutation detection rate of close to $100 \%$ can be achieved if extensive molecular genetic analyses are performed to screen for deep intronic mutations as well as copy-number neutral submicroscopic genomic rearrangements within the CCM1-3 loci. Stringent inclusion criteria are equally important and include high-resolution MRI with $\mathrm{T} 2{ }^{*}$-weighted gradient echo sequences and susceptibility-weighted images of parents in order to select the optimal filter strategy after whole exome or genome sequencing in a research context. The identification of a CCM1-3 mutation influences medical management which is still based on expert opinions and individual risk-benefit analyses as outlined in the 2017 consensus recommendations of the Angioma Alliance Scientific Advisory Board Clinical Experts Panel.

\section{Acknowledgements}

This work was supported by the Deutsche Forschungsgemeinschaft (DFG) (grant DFG-FE432/9-1 to U.F. and grant DFGRA2876/2-1 to M.R.) and by the Research Network Molecular Medicine of the University Medicine Greifswald (grant FOMM2017-03 to S.S.). The authors would like to thank gnomAD and the groups that provided exome and genome variant data to this resource. A full list of contributing groups can be found at http:// gnomad.broadinstitute.org/about.

\section{Disclosure Statement}

The authors declare no conflicts of interest.

\section{References}

Acuna-Hidalgo R, Bo T, Kwint MP, van de Vorst $\mathrm{M}$, Pinelli M, et al: Post-zygotic point mutations are an underrecognized source of de novo genomic variation. Am J Hum Genet 97: 67-74 (2015).

Akers A, Al-Shahi Salman R, A Awad I, Dahlem $\mathrm{K}$, Flemming K, et al: Synopsis of Guidelines for the Clinical Management of Cerebral Cavernous Malformations: Consensus Recommendations Based on Systematic Literature Review by the Angioma Alliance Scientific Advisory Board Clinical Experts Panel. Neurosurgery 80:665-680 (2017).

Akers AL, Johnson E, Steinberg GK, Zabramski JM , Marchuk DA: Biallelic somatic and germline mutations in cerebral cavernous malformations (CCMs): evidence for a twohit mechanism of CCM pathogenesis. Hum Mol Genet 18:919-930 (2009).
Al-Holou WN, O’Lynnger TM, Pandey AS, Gemmete JJ, Thompson BG, et al: Natural history and imaging prevalence of cavernous malformations in children and young adults. J Neurosurg Pediatr 9:198-205 (2012).

Al-Shahi Salman R, Hall JM, Horne MA, Moultrie F, Josephson CB, et al: Untreated clinical course of cerebral cavernous malformations: a prospective, population-based cohort study. Lancet Neurol 11:217-224 (2012).

Batra S, Lin D, Recinos PF, Zhang J, Rigamonti D: Cavernous malformations: natural history, diagnosis and treatment. Nat Rev Neurol 5: 659-670 (2009).

Bergametti F, Denier C, Labauge P, Arnoult M, Boetto S, et al: Mutations within the programmed cell death 10 gene cause cerebral cavernous malformations. Am J Hum Genet 76:42-51 (2005).
Cavé-Riant F, Denier C, Labauge P, Cécillon M, Maciazek J, et al: Spectrum and expression analysis of KRIT1 mutations in 121 consecutive and unrelated patients with cerebral cavernous malformations. Eur J Hum Genet 10: 733-740 (2002).

Cigoli MS, Avemaria F, De Benedetti S, Gesu GP, Accorsi LG, et al: PDCD10 gene mutations in multiple cerebral cavernous malformations. PLoS One 9:e110438 (2014).

Dammann P, Wrede K, Zhu Y, Matsushige T, Maderwald S, et al: Correlation of the venous angioarchitecture of multiple cerebral cavernous malformations with familial or sporadic disease: a susceptibility-weighted imaging study with 7-Tesla MRI. J Neurosurg 126 : 570-577 (2017).

Denier C, Goutagny S, Labauge P, Krivosic V, Arnoult M, et al: Mutations within the MGC4607 gene cause cerebral cavernous malformations. Am J Hum Genet 74:326-337 (2004a). 
Denier C, Labauge P, Brunereau L, Cavé-Riant F, Marchelli F, et al: Clinical features of cerebral cavernous malformations patients with KRIT1 mutations. Ann Neurol 55:213-220 (2004b).

Denier C, Labauge P, Bergametti F, Marchelli F, Riant F, et al: Genotype-phenotype correlations in cerebral cavernous malformations patients. Ann Neurol 60: 550-556 (2006).

de Vos IJ, Vreeburg M, Koek GH, van Steensel MA: Review of familial cerebral cavernous malformations and report of seven additional families. Am J Med Genet A 173:338-351 (2017).

Fauth C, Rostasy K, Rath M, Gizewski E, Lederer AG, et al: Highly variable intrafamilial manifestations of a CCM3 mutation ranging from acute childhood cerebral haemorrhage to late-onset meningiomas. Clin Neurol Neurosurg 128:41-43 (2015).

Flemming KD, Graff-Radford J, Aakre J, Kantarci $\mathrm{K}$, Lanzino G, et al: Population-based prevalence of cerebral cavernous malformations in older adults: Mayo Clinic Study of Aging. JAMA Neurol 74:801-805 (2017).

Gallione CJ, Solatycki A, Awad IA, Weber JL, Marchuk DA: A founder mutation in the Ashkenazi Jewish population affecting messenger RNA splicing of the CCM2 gene causes cerebral cavernous malformations. Genet Med 13: 662-666 (2011).

Gault J, Shenkar R, Recksiek P, Awad IA: Biallelic somatic and germ line CCM1 truncating mutations in a cerebral cavernous malformation lesion. Stroke 36:872-874 (2005).

Gault J, Awad IA, Recksiek P, Shenkar R, Breeze $\mathrm{R}$, et al: Cerebral cavernous malformations: somatic mutations in vascular endothelial cells. Neurosurgery 65:138-144 (2009).

Gianfrancesco F, Cannella M, Martino T, Maglione V, Esposito T, et al: Highly variable penetrance in subjects affected with cavernous cerebral angiomas (CCM) carrying novel CCM1 and CCM2 mutations. Am J Med Genet B Neuropsychiatr Genet 144B:691-695 (2007).

Gross BA, Du R: Hemorrhage from cerebral cavernous malformations: a systematic pooled analysis. J Neurosurg 126:1079-1087 (2017).

Gross BA, Du R, Orbach DB, Scott RM, Smith ER: The natural history of cerebral cavernous malformations in children. J Neurosurg Pediatr 17:123-128 (2016).

Heckl S, Aschoff A, Kunze S: Radiation-induced cavernous hemangiomas of the brain: a late effect predominantly in children. Cancer 94 : 3285-3291 (2002).

Horne MA, Flemming KD, Su IC, Stapf C, Jeon $J P$, et al: Clinical course of untreated cerebral cavernous malformations: a meta-analysis of individual patient data. Lancet Neurol 15: 166-173 (2016).

Knudson AG Jr: Mutation and cancer: statistical study of retinoblastoma. Proc Natl Acad Sci USA 68:820-823 (1971).
Kuhn J, Brummendorf TH, Brassat U, Lehnhardt FG, Chung BD, et al: Novel KRIT1 mutation and no molecular evidence of anticipation in a family with cerebral and spinal cavernous malformations. Eur Neurol 61:154-158 (2009).

Labauge P, Brunereau L, Laberge S, Houtteville JP: Prospective follow-up of 33 asymptomatic patients with familial cerebral cavernous malformations. Neurology 57:1825-1828 (2001).

Laberge-le Couteulx S, Jung HH, Labauge P, Houtteville JP, Lescoat C, et al: Truncating mutations in CCM1, encoding KRIT1, cause hereditary cavernous angiomas. Nat Genet 23:189-193 (1999).

Lek M, Karczewski KJ, Minikel EV, Samocha KE, Banks E, et al: Analysis of protein-coding genetic variation in 60,706 humans. Nature 536: 285-291 (2016).

Limaye N, Revencu N, Van Regemorter N, Garzon M, Bonduelle M, et al: Novel human pathological mutations. Gene symbol: KRIT1. Disease: cerebral cavernous malformation. Hum Genet 122:552 (2007).

Liquori CL, Berg MJ, Siegel AM, Huang E, Zawistowski JS, et al: Mutations in a gene encoding a novel protein containing a phosphotyrosine-binding domain cause type 2 cerebral cavernous malformations. Am J Hum Genet 73:1459-1464 (2003).

Liquori CL, Berg MJ, Squitieri F, Ottenbacher M, Sorlie M, et al: Low frequency of PDCD10 mutations in a panel of CCM3 probands: potential for a fourth CCM locus. Hum Mutat 27:118 (2006).

Lucas M, Costa AF, Montori M, Solano F, Zayas $\mathrm{MD}$, Izquierdo G: Germline mutations in the CCM1 gene, encoding Krit1, cause cerebral cavernous malformations. Ann Neurol 49: 529-532 (2001).

Lucas M, Costa AF, Garcia-Moreno JM, Solano F, Gamero MA, Izquierdo G: Variable expression of cerebral cavernous malformations in carriers of a premature termination codon in exon 17 of the Krit1 gene. BMC Neurol 3:5 (2003).

Marini V, Ferrera L, Pigatto F, Origone P, Garrè $C$, et al: Search for loss of heterozygosity and mutation analysis of KRIT1 gene in CCM patients. Am J Med Genet A 130A:98-101 (2004).

McDonald DA, Shi C, Shenkar R, Gallione CJ, Akers AL, et al: Lesions from patients with sporadic cerebral cavernous malformations harbor somatic mutations in the CCM genes: evidence for a common biochemical pathway for CCM pathogenesis. Hum Mol Genet 23: 4357-4370 (2014).

Melis M, Cau M, Corraine S, Secci S, Addis M, Melis M: Cerebral cavernous malformations and unilateral moyamoya in a patient with a new mutation in the KRIT-1/CCM1 gene. Cerebrovasc Dis 38:311-312 (2014).
Moore SA, Brown RD Jr, Christianson TJ, Flemming KD: Long-term natural history of incidentally discovered cavernous malformations in a single-center cohort. J Neurosurg 120: 1188-1192 (2014)

Nimjee SM, Powers CJ, Bulsara KR: Review of the literature on de novo formation of cavernous malformations of the central nervous system after radiation therapy. Neurosurg Focus 21:e4 (2006).

Otten P, Pizzolato GP, Rilliet B, Berney J: 131 cases of cavernous angioma (cavernomas) of the CNS, discovered by retrospective analysis of 24,535 autopsies (in French). Neurochirurgie 35:82-83 (1989).

Pagenstecher A, Stahl S, Sure U, Felbor U: A twohit mechanism causes cerebral cavernous malformations: complete inactivation of CCM1, CCM2 or CCM3 in affected endothelial cells. Hum Mol Genet 18:911-918 (2009).

Posey JE, Harel T, Liu P, Rosenfeld JA, James RA, et al: Resolution of disease phenotypes resulting from multilocus genomic variation. $\mathrm{N}$ Engl J Med 376:21-31 (2017).

Rath M, Spiegler S, Nath N, Schwefel K, Di Donato $\mathrm{N}$, et al: Constitutional de novo and postzygotic mutations in isolated cases of cerebral cavernous malformations. Mol Genet Genomic Med 5:21-27 (2016).

Rath M, Jenssen SE, Schwefel K, Spiegler S, Kleimeier D, et al: High-throughput sequencing of the entire genomic regions of CCM1/ KRIT1, CCM2 and CCM3/PDCD10 to search for pathogenic deep-intronic splice mutations in cerebral cavernous malformations. Eur J Med Genet 60:479-484 (2017).

Reich P, Winkler J, Straube A, Steiger HJ, Peraud A: Molecular genetic investigations in the CCM1 gene in sporadic cerebral cavernomas. Neurology 60:1135-1138 (2003).

Riant F, Cecillon M, Saugier-Veber P, TournierLasserve E: CCM molecular screening in a diagnosis context: novel unclassified variants leading to abnormal splicing and importance of large deletions. Neurogenetics 14:133-141 (2013).

Riant F, Odent S, Cecillon M, Pasquier L, de Baracé $\mathrm{C}$, et al: Deep intronic KRIT1 mutation in a family with clinically silent multiple cerebral cavernous malformations. Clin Genet 86: 585-588 (2014).

Richards S, Aziz N, Bale S, Bick D, Das S, et al: Standards and guidelines for the interpretation of sequence variants: a joint consensus recommendation of the American College of Medical Genetics and Genomics and the Association for Molecular Pathology. Genet Med 17:405-424 (2015).

Sahoo T, Johnson EW, Thomas JW, Kuehl PM, Jones TL, et al: Mutations in the gene encoding KRIT1, a Krev-1/rapla binding protein, cause cerebral cavernous malformations (CCM1). Hum Mol Genet 8:2325-2333 (1999). 
Schröder W, Najm J, Spiegler S, Mair M, Viera J, et al: Predictive genetic testing of at-risk relatives requires analysis of all $C C M$ genes after identification of an unclassified CCM1 variant in an individual affected with cerebral cavernous malformations. Neurosurg Rev 37: 161-165 (2014).

Shenkar R, Shi C, Rebeiz T, Stockton RA, McDonald DA, et al: Exceptional aggressiveness of cerebral cavernous malformation disease associated with PDCD10 mutations. Genet Med 17:188-196 (2015).

Siegel AM, Andermann E, Badhwar A, Rouleau GA, Wolford GL, et al: Anticipation in familial cavernous angioma: a study of 52 families from International Familial Cavernous Angioma Study. IFCAS Group. Lancet 352: 1676-1677 (1998a).

Siegel AM, Andermann F, Badhwar A, Rouleau GA, Dam M, et al: Anticipation in familial cavernous angioma: ascertainment bias or genetic cause. Acta Neurol Scand 98:372-376 (1998b).
Spiegler S, Najm J, Liu J, Gkalympoudis S, Schröder W, et al: High mutation detection rates in cerebral cavernous malformation upon stringent inclusion criteria: one-third of probands are minors. Mol Genet Genomic Med 2:176-185 (2014).

Spiegler S, Kirchmaier B, Rath M, Korenke GC, Tetzlaff $\mathrm{F}$, et al: $F A M 222 B$ is not a likely novel candidate gene for cerebral cavernous malformations. Mol Syndromol 7:144-152 (2016).

Spiegler S, Rath M, Hoffjan S, Dammann P, Sure $\mathrm{U}$, et al: First large genomic inversion in familial cerebral cavernous malformation identified by whole genome sequencing. Neurogenetics, Epub ahead of print (2017).
Stahl S, Gaetzner S, Voss K, Brackertz B, Schleider $\mathrm{E}$, et al: Novel CCM1, CCM2, and CCM3 mutations in patients with cerebral cavernous malformations: in-frame deletion in CCM2 prevents formation of a CCM1/CCM2/ CCM3 protein complex. Hum Mutat 29:709717 (2008).

Verlaan DJ, Laurent SB, Rochefort DL, Liquori CL, Marchuk DA, et al: CCM2 mutations account for $13 \%$ of cases in a large collection of kindreds with hereditary cavernous malformations. Ann Neurol 55:757-758 (2004).

Washington CW, McCoy KE, Zipfel GJ: Update on the natural history of cavernous malformations and factors predicting aggressive clinical presentation. Neurosurg Focus 29:E7 (2010).

Zabramski JM, Wascher TM, Spetzler RF, Johnson B, Golfinos J, et al: The natural history of familial cavernous malformations: results of an ongoing study. J Neurosurg 80:422-432 (1994). 